\title{
Antibiotic prescribing for endodontic infections: a survey of dental students in Italy
}

\author{
M. Salvadori ${ }^{1}$ D, E. Audino ${ }^{1}$, G. Venturi ${ }^{1}$, M. L. Garo ${ }^{2}$ \& S. Salgarello ${ }^{1}$ \\ ${ }^{1}$ Department of Medical and Surgery Specialties, Radiological Sciences and Public Health, School of Dentistry, Brescia \\ University, Brescia, Italy; and ${ }^{2}$ Independent researcher, Brescia, Italy
}

\begin{abstract}
Salvadori M, Audino E, Venturi G, Garo ML, Salgarello S. Antibiotic prescribing for endodontic infections: a survey of dental students in Italy. International Endodontic Journal.
\end{abstract}

Aim To determine the knowledge of final year undergraduate students attending Italian universities on the appropriate use of systemic antibiotics for endodontic infections.

Methodology Final year dental students from twenty Italian universities completed a one-page questionnaire on antibiotic use for the treatment of endodontic infections. Data were analysed using descriptive statistics and chi-square tests.

Results A total of three hundred and three students completed the questionnaire. The average duration of antibiotic prescription proposed by respondents was $5.48 \pm 1.06$ days. Amoxicillin with clavulanic acid was the first-choice antibiotic (85.2\%) followed by amoxicillin alone (13.5\%), azithromycin (1.0\%) and clarithromycin $(0.3 \%)$, for patients not allergic to penicillin. Clarithromycin was the first-choice drug for patients with a penicillin allergy (56.1\%), followed from azithromycin (31.7\%), clindamycin (11.9\%) and levofloxacin $(0.3 \%)$. Alveolar abscess with systemic manifestations was reported as the principal reason to prescribe antibiotics (97.7\%) followed by the same condition without systemic manifestations (85.5\%). For the scenario of irreversible pulpitis, $5 \%$ of students considered antibiotics necessary. Almost 52\% of students would prescribe antibiotics for apical acute periodontitis; $29.7 \%$ would prescribe antibiotics for chronic apical periodontitis with sinus tract, and $13.5 \%$ indicated these drugs for chronic apical periodontitis without sinus tract.

Conclusions The results demonstrate that it is necessary to improve the knowledge of Italian students on antibiotics and indications for their use in endodontics.

Keywords: antibiotics, dental students survey, endodontic infections.

Received 26 November 2018; accepted 10 April 2019

\section{Introduction}

Although antimicrobial resistance (AMR), one of the principal threats to global public health, is a natural phenomenon, the inappropriate use of antibiotics in humans and animals has accelerated the process with widespread and devastating consequences (WHO

Correspondence: Matteo Salvadori, Department of Medical and Surgery Specialties, Radiological Sciences and Public Health, School of Dentistry, Brescia University, Via Cerreto Basso 2, Bagolino (25072), Brescia, Italy (Tel.: 3388516676; e-mail: salvaz.dori@gmail.com).
2014). AMR increases mortality and morbidity with substantial socioeconomic consequences. In 2007 within Europe alone, there were an estimated 400000 infections and 25000 deaths due to the most frequent multidrug-resistant bacteria (Prestinaci et al. 2015). If no action is taken, it is estimated that drug-resistant infections will kill 10 million people a year by 2050 . AMR threatens the effective prevention and treatment of an ever-increasing range of infections caused by bacteria, parasites, viruses and fungi that are no longer susceptible to the common medicines used to treat them. As healthcare professionals, it is our duty to reassess use of antibiotics in our daily practice. 
A significant proportion of antibiotics are prescribed by dentistry for treatment of minor infections: this practice plays a noteworthy contributing factor in selection of resistance (Pallasch 2000, AAE 2012, Ajantha \& Hegde 2012, Oberoi et al. 2015). Although dental undergraduates are taught that most oral infections may be treated by surgical or chemo-mechanical means without the use of antibiotics, there is growing concern about AMR in dental practice. The inappropriate or misuse of antibiotics in endodontics is the subject of much debate not only in Europe but also in the global scientific community (Mainjot et al. 2009, Rodriguez-Núñez et al. 2009, Segura-Egea et al. 2010, 2017a,b, Perić et al. 2015, AlRahabi \& Abuong 2017, Germack et al. 2017, Bolfoni et al. 2018). The general consensus worldwide is that the widespread prescription of antimicrobials in the treatment of certain endodontic diseases is not appropriate. Evidence to date demonstrates that the routine prescription of antibiotics to prevent infection/pain is to be discouraged unless the patient is symptomatic/ immunocompromised (Cope et al. 2014, Aminoshariae \& Kulild 2016, Segura-Egea et al. 2017a), whilst in certain conditions such as pulpits, periodontitis, and acute local apical abscesses, the use of the antibiotic is positively discouraged. (Fouad et al. 1996, Nagle et al. 2000, Agnihotry et al. 2016). The ESE position statement (ESE 2018) provide dentists with evidence-based criteria for when to use antibiotics in the treatment of endodontic infections, traumatic injuries of the teeth, revascularization procedures in immature teeth with pulp necrosis, and in prophylaxis for medically compromised patient. Dentists have a range of local procedures they can employ to control pain including pulpotomy, pulpectomy, root canal treatment, surgical incision and orthograde drainage or extraction as well as prescription of analgesics. ESE guidelines (ESE 2013) recommend that dental undergraduates should receive training in microbiology and about the mechanisms involved in AMR, as well as in immunology and pain management. They should also receive training in effective infection control in root canal interventions and how to tackle endodontic emergencies such as reversible/irreversible symptomatic pulpitis, symptomatic apical periodontitis and acute apical abscess.

A study conducted in four universities in Spain (Barcelona, Seville, Santiago de Compostela and Zaragoza) (Martín-Jiménez et al. 2018) concluded that whilst the majority of students were aware of the correct management of endodontic infections, others still displayed an inappropriate use of antibiotics. Of particular note was the proposed use of antibiotics in certain situations such as irreversible pulpitis, apical periodontitis, and use of antibiotic therapy for longer than 7 days. The authors concluded that the undergraduate curriculum should provide more focus on good prescribing practices, in particular on the identification and treatment of dental conditions that can be managed without antibiotics. Similarly, Al Masan et al. (2018) evaluated the views of final year dental surgery students at Cardiff University and general dental practitioners within the geographical area of Cardiff, Wales, UK. Results showed that final year dental undergraduates were aware of the antibiotic resistance crisis but around a third of respondents were not aware of guidelines for use of antibiotics in endodontic conditions. Dental undergraduates were more likely than general dental practitioners to prescribe antibiotics for cases of necrotic pulp with symptomatic apical periodontitis without systemic complications and less likely for other clinical scenarios such as necrotic pulp and asymptomatic apical periodontitis for patients with a history of rheumatic fever, symptomatic irreversible/reversible pulpitis, failure to achieve anaesthesia, chronic apical abscess for patients with diabetes.

To date, there are no corresponding data from Italian universities. In Italy, dental students, by the end of the fifth year of their undergraduate course, have already addressed the problem of AMR caused by inappropriate/over use of antibiotics and how to effectively manage endodontic infections. Therefore, the present study was designed to determine the knowledge of undergraduate students in the final year of their dentistry course (sixth year) on the use of systemic antibiotics in endodontic infections.

\section{Materials and methods}

The first stage in the study was to translate and adapt the one-page questionnaire used in the Spanish study to the Italian clinical situation (Table 1) (MartínJiménez et al. 2018). The questionnaire was administered to dental students in the sixth and final year of their undergraduate course in a range of universities throughout Italy. To better determine the knowledge of dentistry students in Italy on the appropriate use of antibiotics and given the historical geographical differences that typify the Italian peninsula, respondents were identified both in relation to their university campus and the geographical area (North, Centre and Mezzogiorno). A professor/tutor from each university 
Table 1 Antibiotic use in endodontic infections questionnaire administered to final year dental undergraduates in Italy

\begin{tabular}{|c|c|c|}
\hline \multicolumn{3}{|l|}{$\begin{array}{l}\text { Gender: } \\
\text { Age: }\end{array}$} \\
\hline Age: & & \\
\hline \multicolumn{3}{|l|}{ Dental school: } \\
\hline \multicolumn{3}{|c|}{$\begin{array}{l}\text { 1) When systemic antibiotics are indicated, which antibiotic } \\
\text { would you choose for the treatment of an endodontic } \\
\text { infection in an adult, healthy patient with no medical } \\
\text { allergies? (only one answer): }\end{array}$} \\
\hline Amoxicillin & $500 \mathrm{mg} \square$ & $1 \mathrm{~g} \square$ \\
\hline Amoxicillin + Clavulanic Acid & $1 \mathrm{~g} \square$ & $-\square$ \\
\hline Azithromycin & $500 \mathrm{mg} \square$ & $-\square$ \\
\hline Clarithromycin & $500 \mathrm{mg} \square$ & $-\square$ \\
\hline $\begin{array}{l}\text { Clindamycin } \\
\text { Other: }\end{array}$ & $300 \mathrm{mg} \square$ & $-\square$ \\
\hline \multicolumn{3}{|c|}{ 2) For how many days would you prescribe antibiotics?: } \\
\hline \multicolumn{3}{|c|}{$\begin{array}{l}\text { 3) When systemic antibiotics are indicated, which antibiotic } \\
\text { would you choose for the treatment of an endodontic } \\
\text { infection in an adult, healthy patient with allergy to } \\
\text { penicillin? (only one answer): }\end{array}$} \\
\hline Azithromycin & $500 \mathrm{mg} \square$ & $-\square$ \\
\hline Clarithromycin & $500 \mathrm{mg} \square$ & $-\square$ \\
\hline $\begin{array}{l}\text { Clindamycin } \\
\text { Other: }\end{array}$ & $300 \mathrm{mg} \square$ & $-\square$ \\
\hline \multicolumn{3}{|c|}{$\begin{array}{l}\text { 4) In which of the following situations do you consider that } \\
\text { antibiotics are indicated? Check all that apply: }\end{array}$} \\
\hline Irreversible pulpitis & & $\square$ \\
\hline Apical acute periodontitis & & $\square$ \\
\hline $\begin{array}{l}\text { Chronic apical periodontitis wi } \\
\text { tract }\end{array}$ & th sinus & $\square$ \\
\hline Chronic apical periodontitis wi & inus tract & $\square$ \\
\hline $\begin{array}{l}\text { Acute apical abscess without s } \\
\text { involvement }\end{array}$ & & $\square$ \\
\hline $\begin{array}{l}\text { Acute apical abscess with syst } \\
\text { involvement (body temperatu } \\
\text { malaise, localized fluctuant sv } \\
\text { lymphadenopathy) }\end{array}$ & $\begin{array}{l}c \\
38^{\circ}, \\
\text { ings, }\end{array}$ & $\square$ \\
\hline
\end{tabular}

dental school administered the questionnaire to students attending regular classes during one specific day and students who were absent from class that day were not included in the study. The respondents' participation was voluntary, anonymous and without any form of remuneration. Administration of the survey and collection of completed questionnaires was carried out over a period of 3 months (from November 2017 to January 2018). Questionnaires received after these dates were not included in the statistical analysis.

Data were collected in an Excel file (Microsoft Corp., Redmond, WA, USA) and analysed using STATA15 software (Stat Corp., College Station, TX, USA). Descriptive statistics were first performed to identify the correct sample composition in relation to gender and age. Frequency distributions were created to describe percentages of responds regarding the use of antibiotics and the cases where respondents considered that the use of antibiotic(s) was appropriate. Statistical significances of these frequency distributions were also analysed using chi-square tests, whilst quantitative data were analysed using U-Mann-Whitney test, given the non-normal distribution of the data. The statistical significance was set at $5 \%$ $(P<0.05)$, and the power sample was examined using the chi-square likelihood-ratio.

\section{Results}

In total, 399 students from 20 universities were enrolled and $303(76 \%)$ completed the questionnaire and were eligible for analysis. Overall, $51.7 \%$ of respondents were male $(n=154)$ and $48.3 \%$ female $(n=144)$. The respondents' mean age was 25.02 years $(\mathrm{SD} \pm 2.65$ years, median $=24$ years $)$ (Table 2). The largest number of respondents were from the University of Turin $(13.86 \%, n=42)$, followed by the University of Catania $(7.6 \%, n=23)$ (Fig. 1).

Considering the three geographical areas, $46.5 \%$ of respondents attended a university in northern Italy $(n=141), \quad 31 \%$ a university in the Mezzogiorno $(n=94)$, and $22.4 \%$ a university in central Italy $(n=68)$.

\section{Prescription and duration of antibiotics}

The average duration of antibiotic prescriptions proposed by respondents was $5.48 \pm 1.06$ days and about half $(50.5 \%)$ indicated a duration of 6 days. Students in northern Italy indicated a longer period of medication (6 days) compared to their counterparts in the South (5 days). This comparison was characterized by a statistical significance at the 5\% level $(P=0.001)$. To better measure the appropriate use of antibiotics by Italian students, a qualitative variable

Table 2 Description of respondents $(n=303)$

\begin{tabular}{ll}
\hline Gender (\%) & \\
Male & $154(51.7)$ \\
Female & $144(48.3)$ \\
Mean age \pm SD (years) & $25.02 \pm 2.65$ \\
Geographical area & \\
North & $141(46.5)$ \\
Centre & $68(22.4)$ \\
Mezzogiorno & $94(31.0)$ \\
\hline
\end{tabular}




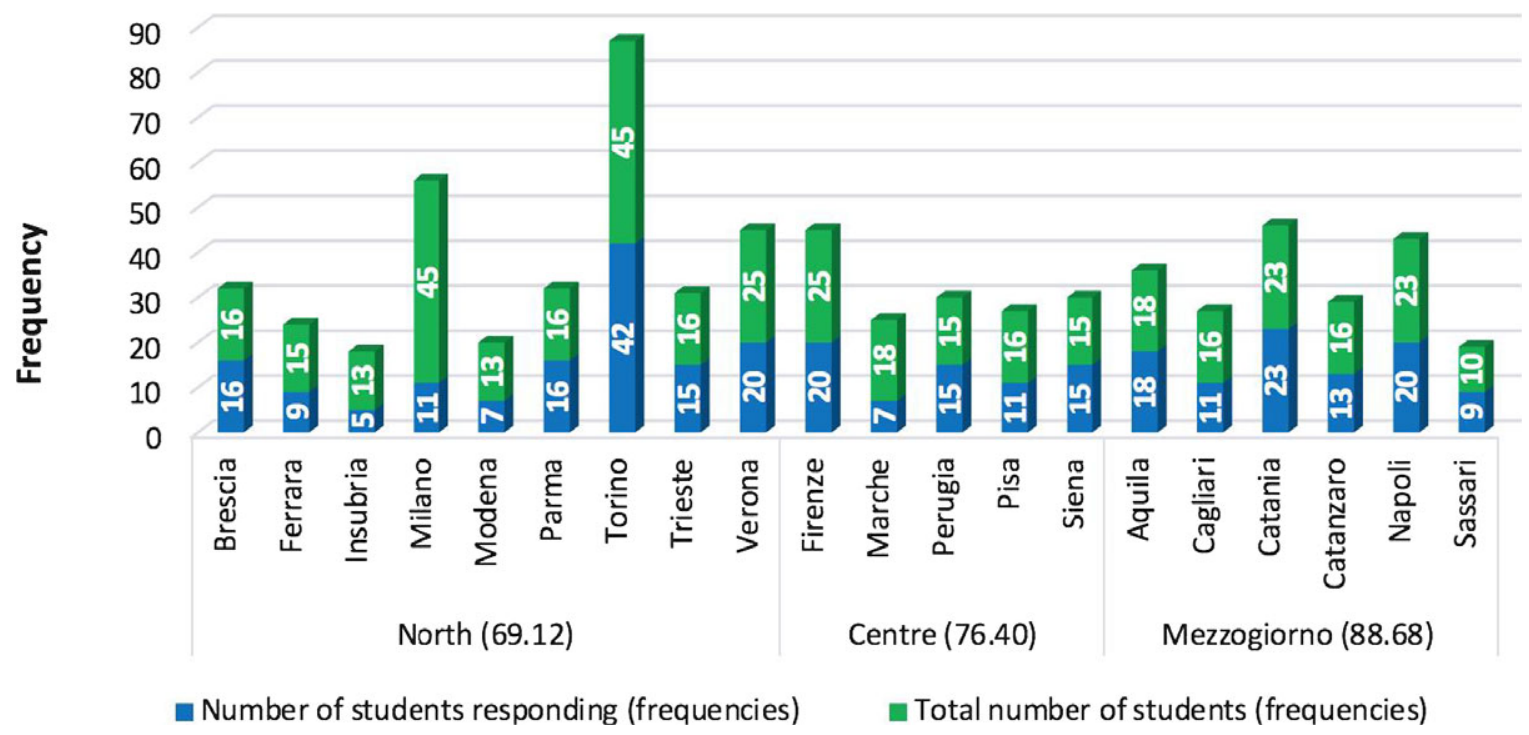

Figure 1 Overall number of students enrolled (frequencies), numbers of respondents by University (frequencies) and percentages of respondents by geographical area in relation to students enrolled.

was created using previous data, called 'range days'. From this analysis $99 \%$ of students indicated a treatment duration of 3-7 days. No significant differences were detected for this variable in relation to the three geographical areas: the majority of students indicated the range of 3-7 days (Table 3).

\section{Indications for use of antibiotics}

Overall 97.7\% $(n=296)$ and $85.5 \%(n=259)$ of students would prescribe antibiotics in cases of alveolar abscess with or without systemic manifestations, respectively (Table 3). In patients with chronic apical periodontitis with sinus tract, $29.7 \%$ of students indicated the possible use of antibiotics, whilst a smaller percentage $(13.5 \%)$ of respondents considered antibiotic treatment was appropriate to treat chronic apical periodontitis without sinus tract. In cases of pulpitis, only $5 \%$ of students indicated the appropriateness of an antibiotic prescription. Observing these values in light of the three geographical areas, alveolar abscess without systemic manifestation was indicated mainly from the northern students $(93.6 \%$, $n=132$ ), and to a lesser extent from the southern students $(78.7 \%)$ and the respondents in the Centre (77.9\%) $(P=0.001)$.

With reference to chronic apical periodontitis with sinus tract, there was a significant difference $(P=0.000)$ between students from the Mezzogiorno, who were more inclined to prescribe antibiotics $(45.7 \%)$, and other students $(19.9 \%$ of northern students, and $27.9 \%$ of students from the Centre), less

Table 3 Duration of antibiotic prescription and therapeutic conditions where use of antibiotics was indicated (results expressed in \% of geographical area, likelihood chi-square ratio)

\begin{tabular}{|c|c|c|c|c|c|}
\hline Duration of therapy (days) & North, $n=141$ & Centre, $n=68$ & Mezzogiorno, $n=94$ & Total & $P$ \\
\hline$<3$ & 0 & 0 & 1.1 & 0.3 & - \\
\hline $3-7$ & 100.0 & 100.0 & 96.8 & 99.0 & - \\
\hline$>7$ & 0 & 0 & 2.2 & 0.7 & - \\
\hline \multicolumn{6}{|c|}{ Therapeutic conditions where use of antibiotics indicated } \\
\hline Alveolar abscess with systemic manifestations & 97.9 & 97.1 & 97.9 & 97.7 & 0.926 \\
\hline Alveolar abscess without systemic manifestations & 93.6 & 77.9 & 78.7 & 85.5 & 0.001 \\
\hline Chronic apical periodontitis with sinus tract & 19.9 & 27.9 & 45.7 & 29.7 & 0.000 \\
\hline Chronic apical periodontitis without sinus tract & 23.4 & 5.9 & 4.3 & 13.5 & 0.000 \\
\hline Acute apical periodontitis & 56.7 & 23.5 & 64.9 & 51.8 & 0.000 \\
\hline Pulpitis & 2.1 & 7.4 & 7.5 & 5.0 & 0.107 \\
\hline
\end{tabular}


inclined to use antibiotics. Considering chronic apical periodontitis without sinus tract, there was a decisive decrease in percentages for all three Italian areas: antibiotic treatment was considered suitable by $23.4 \%$ of students in the North, 5.9\% of students in the Centre, and for $4.3 \%$ of southern students $(P=0.000)$. Finally, there were significant differences $(P=0.000)$ amongst students in relation to acute apical periodontitis $64.9 \%$ of students in the South indicated the correctness of the antibiotic use in these cases, followed by $56.7 \%$ of northern students. Only students in the Centre did not indicate antibiotics as a suitable treatment $(23.5 \%)$.

\section{First-choice antibiotic}

Amoxicillin in combination with clavulanic acid was the first and most indicated choice for patients without penicillin allergy $(85.2 \%, n=258)$. Amoxicillin alone represented the first-choice antibiotic for $13.5 \%$ $(n=41)$ of students, whilst azithromycin and clarithromycin were first-choice antibiotics for $1 \%(n=3)$ and $0.3 \%(n=1)$, respectively.

Amoxicillin/clavulanic acid $1 \mathrm{~g}$ was selected by $98.8 \%(n=255)$ of respondents, whilst amoxicillin $1 \mathrm{~g}$ alone was indicated by $70.7 \%$ of students. Furthermore, $29.3 \%$ of respondents indicated they would prescribe amoxicillin $500 \mathrm{mg}$ alone, whilst $1.2 \%$ $(n=3)$ would prescribe amoxicillin $500 \mathrm{mg}$ combined with clavulanic acid. Amoxicillin $500 \mathrm{mg}$ was indicated by $75 \%$ of students from the South, whilst $91.3 \%$ of northern students and $83.3 \%$ of students from the Centre recommended amoxicillin $1 \mathrm{~g}$
(Table 4). In addition, amoxicillin $1 \mathrm{~g}$ combined with clavulanic acid was the most selected option and only a small percentage of students $(4.8 \%)$ chose amoxicillin/clavulanic acid $500 \mathrm{mg}$.

\section{Second-choice antibiotic}

When the data on the second-choice antibiotic (suitable for allergic patients) was analysed, there was a greater heterogeneity compared to that noted with the first-choice antibiotic: $56.1 \%(n=170)$ of respondents stated they would prescribe clarithromycin, $31.7 \%(n=96)$ of students considered that azithromycin was appropriate, and $11.9 \%$ considered clindamycin as an appropriate treatment for patients allergic to penicillin. Combining data on the secondchoice antibiotics and recommended dosages, clarithromycin $500 \mathrm{mg}$ and azithromycin $500 \mathrm{mg}$ were the most indicated: $98.8 \%$ of respondents would prescribe clarithromycin as a second-choice antibiotic and $99 \% \quad(n=95)$ azithromycin (Table 4), whilst $62.9 \%$ and $37.1 \%$ of students would prescribe clindamycin $300 \mathrm{mg}$ and $600 \mathrm{mg}$, respectively. These percentages were characterized by a significant difference at level of $1 \%(P=0.000)$ and the sample had an excellent representativeness of population as emerged from the power test (power $=1.000$ ).

\section{Discussion}

The results of this study provide a wide range of data on the use of antibiotics in endodontic infections by dental students within Italy. The results also identify

Table 4 Antibiotic preferences (\%)

\begin{tabular}{|c|c|c|c|c|c|c|c|}
\hline & Antibiotic & Dose & $\begin{array}{l}\text { Nord, } \\
n=141\end{array}$ & $\begin{array}{l}\text { Centre, } \\
n=68\end{array}$ & $\begin{array}{l}\text { Mezzogiorno, } \\
n=94\end{array}$ & Total & $P$ \\
\hline \multirow{7}{*}{$\begin{array}{l}\text { Patients without penicillin } \\
\text { allergy }\end{array}$} & Amoxicillin & $500 \mathrm{mg}$ & 8.7 & 16.7 & 75.0 & 29.3 & 0.000 \\
\hline & & $1 \mathrm{~g}$ & 91.3 & 83.3 & 25.0 & 70.7 & \\
\hline & Amoxicillin + Clavulanic & $500 \mathrm{mg}$ & & 4.8 & & 1.2 & 0.008 \\
\hline & Acid & $1 \mathrm{~g}$ & 100.0 & 95.2 & 100.0 & 98.8 & \\
\hline & Azithromycin & $500 \mathrm{mg}$ & & & 100.0 & 100.0 & - \\
\hline & Clarithromycin & $500 \mathrm{mg}$ & 100.0 & & & 100.0 & - \\
\hline & Clindamycin & $500 \mathrm{mg}$ & & & & 0.0 & - \\
\hline \multirow{8}{*}{$\begin{array}{l}\text { Patients with penicillin } \\
\text { allergy }\end{array}$} & Azithromycin & $500 \mathrm{mg}$ & 100.0 & 100.0 & 97.7 & 99.0 & 0.536 \\
\hline & Clarithromycin & $1 \mathrm{~g}$ & & & 2.3 & 1.0 & \\
\hline & & $500 \mathrm{mg}$ & 97.9 & 100.0 & 100.0 & 98.8 & 0.810 \\
\hline & & $600 \mathrm{mg}$ & 0.6 & & & 0.6 & \\
\hline & & $1 \mathrm{~g}$ & 1.1 & & & 0.6 & \\
\hline & Clindamycin & $300 \mathrm{mg}$ & 40.0 & 80.0 & 80.0 & 62.9 & 0.053 \\
\hline & & $600 \mathrm{mg}$ & 60.0 & 20.0 & 20.0 & 37.1 & \\
\hline & Levofloxacin & $500 \mathrm{mg}$ & & 100.0 & & 100.0 & - \\
\hline
\end{tabular}


areas where interventions may be required to increase their knowledge base and skills, with the overall objective of reducing the percentage of students who still use antibiotic therapy inappropriately.

Overall, 399 students from 20 universities in Italy participated. Its main strengths were that the large cohort ensured results were representative of the overall population and that students surveyed were in regular attendance at classes. Data were analysed according to: gender, age, geographical area of university, first-choice antibiotic (beta-lactam antibiotic), duration of antibiotic therapy, second choice antibiotic (antibiotic not beta-lactam) and reasons for the use of antibiotics. The sample mean age was $25.0 \pm 2.7$ years.

The average duration of antibiotic therapy proposed by Italian students was $5.5 \pm 1.1$ days. Furthermore, $99 \%$ of Italian students indicated a treatment from 37 days, with $0.1 \%$ selecting a duration of $>7$ days. In contrast, Martín-Jiménez et al. (2018) reported that $20 \%$ of Spanish students prescribed antibiotics $>7$ days. In general, endodontic infections have a rapid and short onset and generally last from 3 to 7 days so treatment for less than 7 days is indicated, although both scenarios are broadly in line with literature recommendations (Segura-Egea et al. 2017a).

Amoxicillin was indicated as the first-choice antibiotic by $99 \%$ of Italian respondents with $29 \%$ of students indicating it should be administered alone, whilst the remaining $71 \%$ considered that it should be prescribed in combination with clavulanic acid. Regarding the use of Amoxicillin as a first-choice antibiotic, the results agree with those reported by Martín-Jiménez et al. (2018): in that study Amoxicillin was chosen by $100 \%$ of the respondents. Lower percentages are collected by Guzmán-Álvarez et al. (2012) and by Jain et al. (2015): however, the data obtained on the students of the respective universities confirm that Amoxicillin was indicated as the most prescribed molecule. Amoxicillin, a moderate-spectrum beta-lactam antibiotic, is suitable for endodontic infections (Skucaite et al. 2010, Segura-Egea et al. 2017a) as it provides coverage for gram-positive, gram-negative, anaerobic and strictly anaerobic bacteria. However, its effectiveness is reduced when the same infections are sustained by beta-lactamase-producing bacteria. Amoxicillin is therefore frequently administered in combination with clavulanic acid, which improves its bactericidal effect, despite the fact that in this case the risk of Clostridium Difficile infection increases (Gordon 2010, Chilton et al. 2012). Furthermore, although the combination of amoxicillin with clavulanic acid is characterized by a broader spectrum of action, it carries a higher risk of developing resistant bacteria (Barcelona et al. 2008, Montagner et al. 2014).

Data from the literature confirm that amoxicillin alone and in combination with clavulanic acid represents an optimal first-choice antibiotic in the treatment of endodontic infections, although care should be taken to ensure the correct dosage/duration is used (ESE 2018).

Clarithromycin was the second-choice antibiotic in patients allergic to $\beta$-lactam antibiotics with $56 \%$ of Italian students citing a preference for this drug, whilst Martín-Jiménez et al. (2018) reported that 99\% of respondents would prescribe clindamycin $300 \mathrm{mg}$. Referring to odontogenic infections, Jain et al. (2015) and Guzmán-Álvarez et al. (2012) reported Clindamycin as the most prescribed antibiotic in case of penicillin allergy. These results are in line with protocols that recommend the use of clindamycin, clarithromycin or azithromycin in patients allergic to beta-lactam antibiotics (ESE 2018).

Antibiotic therapy is indicated in healthy patients with acute apical abscess with systemic involvement (localized swelling, body temperature $>38{ }^{\circ} \mathrm{C}$, lymphadenopathy, trismus), in progressive infections (severe infection with rapid onset, less than $24 \mathrm{~h}$, cellulitis or diffuse infection, osteomyelitis) where onward referral to oral surgery is necessary, in the re-implantation of a permanent tooth following avulsion and in soft tissue trauma requiring treatment (ESE 2018). Acute apical abscess is characterized by rapid onset, spontaneous pain, pus formation and swelling associated with the soft tissues. Over $90 \%$ of Italian students considered the prescription of the antibiotics necessary in acute apical abscess with systemic manifestations. These results provide confirmation that they were able to correctly recognize the clinical scenario in which the adoption of systemic antibiotic therapy is necessary. Interestingly, $86 \%$ of Italian respondents indicated that antibiotic prescription is required in patients with acute apical abscess without systemic involvement. The general consensus is that treatment aimed at intracanal or surgical drainage is sufficient to control the infection and systemic antibiotic therapy is not necessary (Segura-Egea et al. 2017a). Similarly, the use of an antibiotic is considered ineffective in patients with symptomatic irreversible pulpitis because it does not stop the processes of necrosis and does not reduce symptomatology (George 2014, Hoskin \& Veitz-Keenan 2016). In line 
with recommendations, only $5 \%$ of respondents in this study would prescribe an antibiotic for pulpitis. Higher percentages are reported by Martín-Jiménez et al. (2018) and Al Masan et al. (2018), respectively, $65 \%$ and $25 \%$ of respondents. It is probable that this difference can be attributed to the differences in the curriculum, and not to the methodology used to collect the answers. In fact, the present study used the same methodology described by Martín-Jiménez et al. (2018) providing students with the diagnosis so to help them in their decision-making process. On the contrary, Al Masan et al. (2018) provided Cardiff students with a series of clinical scenarios in which each student chose to use or not use of antibiotics in accordance with the specific scenario proposed. Because Italian universities share the same diagnostic terminology, Italian students are correctly focused on recognizing endodontic disorders and associating them with their respective clinical scenarios.

As regard acute apical periodontitis, 52\% of Italian students would prescribe antibiotics. Similarly, Martín-Jiménez et al. (2018) and Al Masan et al. (2018) report that $44 \%$ and $75 \%$ of the students, respectively, indicated the antibiotic in the treatment of teeth with necrotic pulp and symptoms of apical periodontitis. Antibiotics are ineffective in controlling pain in endodontic infections (Fouad et al. 1996, Henry et al. 2001, Keenan et al. 2006, Cope et al. 2014). Instead, the recommended management of acute apical periodontitis is the prescription of analgesics and anti-inflammatories (Agnihotry et al. 2016), and / or with the treatment of the root canal (Paredes-Vieyra \& Enriquez 2012).

Inappropriate use of antibiotics emerged in the management of chronic apical periodontitis with and without fistula, where $30 \%$ and $14 \%$, respectively, of respondents from Italian universities and 38\% and 16\% from Spain (Martín-Jiménez et al. 2018) replied that they would prescribe antibiotics for these conditions. Moreover, the larger percentage of respondents who would use antibiotics for chronic apical periodontitis with fistula, suggests that students erroneously believe the presence of a fistula, in dental infections, is a symptomatic indication of worsening condition, whereas the fistula represents an orifice which connects a closed area of an infection with an epithelial surface-whereby internal pressure can be discharged, thus helping to prevent swelling, pain and spread of the infection in the anatomical spaces. The presence of fistula does not mean an exacerbated endodontic infection and chronic apical periodontitis associated with fistula should be treated with a canal treatment and intermediate medications but not with antibiotics (Mittal \& Gupta 2004).

The results of this study provide useful data on the state of knowledge of final year undergraduate dental students and demonstrate where gaps in their knowledge exist. To deadline these deficiencies, it is necessary that students improve their knowledge of the biological and microbiological principles underlying inflammation and infection and now to best manage these conditions. One of the main messages to emerge is that the misuse/inappropriate use of antibiotics is effectively associated with a lack of knowledge on the part of those who prescribe them, combined with lack of awareness from patients who frequently expect to be treated with an antibiotic-erroneously associating the use of antibiotics with therapeutic advantages and the reduction of pain (Cope et al. 2014, MartínJiménez et al. 2018).

\section{Conclusions}

The inappropriate use of systemic antibiotics in endodontic infections contributes to the growing public health problem of AMR. The results confirm that newly qualified dentists should receive training in line with international guidelines on the appropriate use of antibiotics in their daily practice. Results of the present study identified where gaps in knowledge and training existed, and it is vital that they are effectively incorporated into undergraduate dentistry courses to ensure dentists of the future have the necessary tools for the effective prevention and treatment of infections and to work towards addressing the devastating consequences of AMR.

\section{Acknowledgements}

The authors would like to thank all professors, their collaborators, and students who kindly took part in this study. In particular, we will be pleased to mention: Professor Angerame Daniele, Professor Berutti Elio, Professor Cotti Elisabetta, Professor Dionisi Anna Maria, Professor Eramo Stefano, Professor Fortunato Leonzio, Professor Fumei Gianluca, Professor Gagliani Massimo, Professor Generali Luigi, Professor Gerosa Roberto, Professor Grandini Simone, Professor Milia Egle Patrizia, Professor Pace Riccardo, Professor Pizzi Silvia, Professor Rapisarda Ernesto, Professor Rengo Sandro, Professor Tosco Eugenio, Professor Vano Michele, Professor Vecchiantini Renata for their support. 


\section{Conflict of interest}

The authors have stated explicitly that there are no conflicts of interest in connection with this article.

\section{REFERENCES}

Agnihotry A, Fedorowicz Z, Van Zuuren EJ, Farman AG, AlLangawi JH (2016) Antibiotic use for irreversible pulpitis. The Cochrane Library 2, CD004969.

Ajantha GS, Hegde V (2012) Antibacterial drug resistance and its impact on dentistry. New York State Dental Journal 78, 38-41.

Al Masan AA, Dummer PMH, Farnell DJJ, Vianna ME (2018) Antibiotic prescribing for endodontic therapies: a comparative survey between general dental practitioners and final year Bachelor of Dental Surgery students in Cardiff, UK. International Endodontic Journal 51, 717-28.

AlRahabi MK, Abuong ZA (2017) Antibiotic abuse during endodontic treatment in private dental centers. Saudi Medical Journal. 38, 852-6.

American Association of Endodontists (AAE) (2012) Use and abuse of antibiotics. AAE: Endodontics Colleagues for Excellence, $1-8$.

Aminoshariae A, Kulild JC (2016) Evidence-based recommendations for antibiotic usage to treat endodontic infections and pain: a systematic review of randomized controlled trials. The Journal of American Dental Association 147, 186-91.

Barcelona L, Marın M, Stamboulian D (2008) Betalactam antibiotics combined with bectalactamases inhibitors. Amoxicillin-sulbactam. Medicina (B Aires) 68, 65-74.

Bolfoni MR, Pappen FG, Pereira-Cenci T, Jacinto RC (2018) Antibiotic prescription for endodontic infections: a survey of Brazilian Endodontists. International Endodontic Journal 51, 148-56.

Chilton CH, Freeman J, Crowther GS, Todhunter SL, Nicholson S, Wilcox MH (2012) Co-amoxiclav induces proliferation and cytotoxin production of Clostridium difficile ribotype 027 in a human gut model. Journal of Antimicrobial Chemotherapy 67, 951-4.

Cope A, Francis N, Wood F, Mann MK, Chestnutt IG (2014) Systemic antibiotics for symptomatic apical periodontitis and acute apical abscess in adults. Cochrane Database Systematic Reviews 26, CD010136.

ESE (2013) Undergraduate curriculum guidelines for Endodontology. International Endodontic Journal 46, 110514.

ESE (2018) European Society of Endodontology position statement: the use of antibiotics in endodontics. International Endodontic Journal 51, 20-5.

Fouad AF, Rivera EM, Walton RE (1996) Penicillin as a supplement in resolving the localized acute apical abscess.
Oral Surgery, Oral Medicine, Oral Pathology, Oral Radiology and Endodontology 81, 590-5.

George R (2014) Insufficient evidence to assess the effectiveness of antibiotics for irreversible pulpitis. Evidence Based Dentistry 15, 10-1.

Germack M, Sedgley CM, Sabbah W, Whitten B (2017) Antibiotic Use in 2016 by Members of the American Association of Endodontists: Report of a National Survey. Journal of Endodontics 43, 1615-22.

Gordon D (2010) Amoxicillin-Clavulanic Acid (Co-Amoxiclav). In: Grayson ML, Cosgrove SE, Crowe S, Hope W, McCarthy JS, Mills J, Mouton JW, Paterson DL, eds. Kucers' the use of Antibiotics: a Clinical Review of Antibacterial, Antifungal, Antiparasitic and Antiviral Drugs. London, UK: Hodder Arnold/ASM Press, pp. 193-4.

Guzmán-Álvarez R, Medeiros M, Reyes Lagunes LI, CamposSepúlveda A (2012) Knowledge of drug prescription in dentistry students. Drug Healthcare and Patient Safety 4, 55-9.

Henry M, Reader A, Beck M (2001) Effect of penicillin on postoperative endodontic pain and swelling in symptomatic necrotic teeth. Journal of Endodontics 27, 117-23.

Hoskin E, Veitz-Keenan A (2016) Antibiotics are not useful to reduce pain associated with irreversible pulpitis. Evidence Based Dentistry 17, 81-2.

Jain A, Gupta D, Singh D et al. (2015) Knowledge regarding prescription of drugs among dental students: a descriptive study. Journal of Basic and Clinical Pharmacy 7, 12-6.

Keenan JV, Farman AG, Fedorowicz Z, Newton JT (2006) A Cochrane systematic review finds no evidence to support the use of antibiotics for pain relief in irreversible pulpitis. Journal of Endodontics 32, 87-92.

Mainjot A, D'Hoore W, Vanheusden A, Van Nieuwenhuysen JP (2009) Antibiotic prescribing in dental practice in Belgium. International Endodontic Journal 42, 1112-7.

Martín-Jiménez M, Martín-Biedma B, López-López J et al. (2018) Dental students' knowledge regarding the indications for antibiotics in the management of endodontic infections. International Endodontic Journal 51, 118-27.

Mittal N, Gupta P (2004) Management of extra oral sinus cases: a clinical dilemma. Journal of Endodontics 30, 5417.

Montagner F, Jacinto RC, Correa Signoretti FG, Scheffer de Mattos V, Grecca FS, Gomes BP (2014) Beta-lactamic resistance profiles in Porphyromonas, Prevotella, and Parvimonas species isolated from acute endodontic infections. Journal of Endodontics 40, 339-44.

Nagle D, Reader A, Beck M, Weaver J (2000) Effect of systemic penicillin on pain in untreated irreversible pulpitis. Oral Surgery, Oral Medicine, Oral Pathology, Oral Radiology and Endodontology 90, 636-40.

Oberoi SS, Dhingra C, Sharma G, Sardana D (2015) Antibiotics in dental practice: how justified are we. International Dental Journal 65, 4-10. 
Pallasch TJ (2000) Global antibiotic resistance and its impact on the dental community. Journal of the Californian Dental Association 28, 215-33.

Paredes-Vieyra J, Enriquez FJ (2012) Success rate of singleversus two-visit root canal treatment of teeth with apical periodontitis: a randomized controlled trial. Journal of Endodontics 38, 1164-9.

Perić M, Perković I, Romić M, Simeon P, Matijević J, Mehičić GP (2015) The Pattern of Antibiotic Prescribing by Dental Practitioners in Zagreb, Croatia. Central European Journal of Public Health 23, 107-13.

Prestinaci F, Pezzotti P, Pantosti A (2015) Antimicrobial resistance: a global multifaceted phenomenon. Pathogens and Global Health 109, 309-18.

Rodriguez-Núñez A, Cisneros-Cabello R, Velasco-Ortega E, Llamas-Carreras JM, Tórres-Lagares D, Segura-Egea JJ (2009) Antibiotic use by members of the Spanish Endodontic Society. Journal of Endodontics 35, 1198-203.

Segura-Egea JJ, Velasco-Ortega E, Torres-Lagares D, VelascoPonferrada MC, Monsalve-Guil L, Llamas-Carreras JM
(2010) Pattern of antibiotic prescription in the management of endodontic infections amongst Spanish oral surgeons. International Endodontic Journal 43, 342-50.

Segura-Egea JJ, Gould K, Şen BH et al. (2017a) Antibiotics in Endodontics: a review. International Endodontic Journal 50, 1169-84.

Segura-Egea JJ, Martin-Gonzalez J, Jimenez-Sanchez MC, Crespo-Gallardo I, Saúco-Márquez JJ, Velasco Ortega E (2017b) Worldwide pattern of antibiotic prescription in endodontic infections. International Dental Journal 64, 197205.

Skucaite N, Peciuliene V, Vitkauskiene A, Machiulskiene V (2010) Susceptibility of endodontic pathogens to antibiotics in patients with symptomatic apical periodontitis. Journal of Endodontics 36, 1611-6.

World Health Organization (WHO) (2014) Antimicrobial Resistance Global Report on Surveillancehttp://apps.who. int/iris/bitstream/handle/10665/112642/9789241564748_ eng.pdf;jsessionid = 276CEDC7BBC1392E12CB0B5C5C9E11 47 ? sequence $=1$ (Accessed on September 2017). 